\title{
SISTEM PENDUKUNG KEPUTUSAN PEMILIHAN PENYULUH LAPANGAN KELUARGA BERENCANA TELADAN DENGAN METODE WEIGHTED PRODUCT
}

\author{
Rezqiwati Ishak \\ rezqi.uig@gmail.com \\ Fakultas IImu Komputer Universitas Ichsan Gorontalo
}

\begin{abstract}
Abstrak
Penyuluh lapangan keluarga berencana (PLKB) adalah Pegawai Negeri Sipil yang diberi tugas, tanggungjawab, wewenang, dan hak secara penuh oleh pejabat yang berwenang untuk melaksanakan kegiatan penyuluhan, pelayanan, evaluasi dan pengembangan KB Nasional. Pemilihan PLKB Teladan ini dilaksanakan sekali setiap tahunnya. Masalah yang dihadapi dalam proses penyeleksian PLKB adalah banyaknya jumlah pemohon sementara yang akan ditetapkan menjadi Penyuluh Teladan hanya 1 orang sehingganya memerlukan proses penyeleksian yang benar-benar akurat berdasarkan kriteria yang ditentukan. Untuk itu Sistem Pendukung Keputusan sangatlah dibutuhkan. Adapun metode yang digunakan adalah Weighted product. Dari hasil penelitian yang didapatkan bahwa sistem tersebut dapat membantu pihak penyeleksi dapat menentukan PLKB Teladan. Hal ini dibuktikan dengan hasil pengujian yang dilakukan dengan metode white box testing dan basis path testing yang menghasilkan nilai yang sama, sehingga didapat bahwa logika flowchart perhitungan, penilaian dan perankingan benar dan berdasarkan pengujian black box rancangan perangkat lunak telah terpenuhi dengan hasil sesuai dengan rancangan.
\end{abstract}

Kata kunci : Penyuluh Keluarga Berencana, WP, MADM.

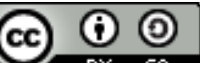

ILKOM Jurnal Ilmiah work is licensed under a CCA-SA 4.0 International License.

\section{Pendahuluan}

Penyuluh lapangan keluarga berencana (PLKB) adalah Pegawai Negeri Sipil yang diberi tugas, tanggungjawab, wewenang dan hak secara penuh oleh pejabat yang berwenang untuk melaksanakan kegiatan penyuluhan, pelayanan, evaluasi dan pengembangan KB Nasional yang ditempatkan di lingkungan instansi pemerintah baik di tingkat pusat maupun daerah. PLKB juga sebagai dituntut untuk mendinamisasi, memfasilitasi keluarga dan masyarakat untuk memenuhi kebutuhannya serta penyampaian informasi dalam rangka meningkatkan pengetahuan, sikap dan perilaku keluarga dan masyarakat untuk mewujudkan keluarga berkualitas. [1].

Mengacu kepada Keputusan Presiden Nomor 9 Tahun 2004 tentang Jabatan Fungsional Penyuluh Keluarga Berencana dan Angka Kreditnya, kegiatan Pemilihan Penyuluh Lapangan Keluarga Berencana (PLKB) Teladan ini dilaksanakan sekali setiap tahunnya, dimana jumlah penyuluh lapangan keluarga berencana saat ini di Kota Gorontalo berjumlah 96 orang, sementara yang akan diterima sebagai Penyuluh Lapangan Keluarga Berencana Teladan hanya 1 orang. Adapun reward yang diberikan kepada penyuluh lapangan keluarga berencana teladan yang terpilih diantaranya berupa piagam penghargaan, tiket pesawat dan sejumlah uang. [2].

Permasalahan yang muncul disini adalah sulitnya menentukan 1 peserta yang akan dipilih diantara sejumlah peserta yang mendaftar, sehingganya Team penyeleksi dalam hal ini pihak Badan Pemberdayaan Masyarakat Perempuan dan Keluarga Berencana Kota Gorontalo harus selektif dalam melakukan penyeleksian dengan berdasar pada kriteria yang telah ditentukan. Adapun kriteria yang digunakan sebagai parameter penyeleksian adalah, usia maksimal 60 tahun, status penyuluh (Pegawai Negeri Sipil), memiliki tanggungan maksimal 2 anak, suami atau istri menggunakan alat kontrasepsi MKJP (Metode Kontrasefsi Jangka Panjang), minimal 4 tahun sebagai penyuluh KB. [2]. untuk itu diperlukan sebuah sistem pendukung keputusan untuk membantu pihak BPMPKB dalam pengambilan suatu keputusan.

Adapun metode yang digunakan dalam sistem pendukung keputusan ini adalah metode Weighted Product (WP), metode ini dipilih karena metode ini merupakan salah satu metode penyelesaian yang ditawarkan untuk menyelesaikan masalah Multiple Attribute Decision Making (MADM). Metode ini adalah metode yang sederhana dalam proses penyelesaiannya karena hanya melalui 3 tahapan yakni penentuan nilai bobot dari masing-masing kriteria, menentukan nilai dari vektor $S$ dan menentukan nilai dari vektor $V$ yakni tahapan perangkingan. [3]. Sehingga nilai yang didapatkan lebih tepat dan akurat karena didasarkan pada nilai masing-masing kriteria beserta bobotnya. Dari proses ini akan didapatkan peserta yang benar-benar layak terpilih menjadi Penyuluh Lapangan Keluarga Berencana (PLKB) Teladan. 


\section{Landasan Teori}

\subsection{Pengertian Sistem Pendukung Keputusan}

Menurut Turban (2005: 30), Sistem Pendukung Keputusan terdiri dari 4 sub sistem yaitu: 1).Manajemen Data, meliputi basis data yang berisi data-data yang relevan dengan keadaan dan dikelola oleh perangkat lunak yang disebut Database Management System (DBMS). 2).Manajemen Model berupa sebauh paket perangkat lunak yang berisi model-model finansial, statistik, management science, atau model kuantitatif yang menyediakan kemampuan analisa dan perangkat lunak manajemen yang sesuai. 3).Subsistem Dialog atau komunikasi, merupakan subsistem yang dipakai oleh user untuk berkomunikasi dan memberi perintah (menyediakan user interface). 4).Manajemen Knowledge yang mendukung subsistem lain atau berlaku sebagai komponen yang berdiri sendiri. [4].

Konsep Sistem Pendukung Keputusan (SPK) atau Decision Support Systems (DSS) pertama kali diungkapkan pada awal tahun 1970-an oleh Michael S. Scott Morton dengan istilah Management Decision Systems. Morton, et al mendefinisikan DSS sebagai "Sistem Berbasis Komputer Interaktif, yang membantu para pengambil keputusan untuk menggunakan data dan berbagai model untuk memecahkan masalah-masalah yang tidak terstruktur". [4]

DSS (Decision Support Systems) biasanya dibangun untuk mendukung solusi atas suatu masalah atau untuk mengevaluasi suatu peluang. DSS yang seperti itu disebut aplikasi DSS. Aplikasi DSS digunakan dalam pengambilan keputusan. Aplikasi DSS menggunakan CBIS (Computer Based Information Systems) yang fleksibel, interaktif dan dapat diadaptasi yang dikembangkan untuk mendukung solusi atas masalah manajemen spesifik yang tidak terstruktur. [5]

Pada dasarnya SPK ini merupakan pengembangan lebih lanjut dari Sistem Informasi Manajemen Terkomputerisasi (Computerized Manajement Information Systems), yang dirancang sedemikian rupa sehingga bersifat interaktif dengan pemakainya. Sifat interaktif ini dimaksudkan untuk memudahkan integrasi antara berbagai komponen dalam proses pengambilan keputusan, seperti prosedur, kebijakan, teknik analisis, serta pengalaman dan wawasan manajerial guna membentuk suatu kerangka keputusan yang bersifat fleksibel

\subsection{Karakteristik Sistem Pendukung Keputusan}

Menurut Turban (2005) dalam Kusrini (2007:20), Karakteristik dan kapabilitias kunci dari Sistem Pendukung Keputusan adalah sebagai berikut :

1. Dukungan untuk pengambil keputusan, terutama pada situasi semi terstruktur dan tak terstruktur.

2. Dukungan untuk semua level manajerial, dari eksekutif puncak sampai manajer lini.

3. Dukungan untuk individu dan kelompok.

4. Dukungan untuk semua keputusan independen dan sekuensial.

5. Dukungan di semua fase proses pengambilan keputusan: intelegensi, desain, pilihan, dan implementasi.

6. Dukungan pada berbagai proses dan gaya pengambilan keputusan.

7. Kemampuan sistem beradaptasi dengan cepat dimana pengambil keputusan dapat menghadapi masalah-masalah baru dan pada saat yang sama dapat menanganinya dengan cara mengadaptasikan sistem terhadap kondisi-kondisi perubahan yang terjadi.

8. Pengguna merasa seperti di rumah. User-friendly, kapabilitas grafis yang kuat dan sebuah bahasa interaktif yang alami.

9. Peningkatan terhadap keefektifan pengambilan keputusan (akurasi, time lines, kualitas) dari pada efisiensi (biaya).

10.Pengambil keputusan mengontrol penuh semua langkah proses pengambilan keputusan dalam memecahkan masalah.

11.Pengguna akhir dapat mengembangkan dan memodifikasi situasi pengambilan keputusan.

12.Menggunakan model-model dalam penganalisisan situasi pengambilan keputusan.

13.Disediakannya akses untuk berbagai sumber data, format dan tipe, mulai dari sistem informasi geografis (GIS) sampai sistem berorientasi objek.

14.Dapat dilakukan sebagai alat standalone yang digunakan oleh seorang pengambil keputusan pada satu lokasi atau di distribusikan di satu organisasi keseluruhan dan di beberapa organisasi sepanjang rantai persediaan.

\subsection{Konsep Dasar Multiple Attribute Decision Making (MADM)}

MADM adalah salah satu metode yang digunakan untuk mencari alternatif optimal dari sejumlah alternatif dengan kriteria-kriteria tertentu. Inti dari Multiple Attribute Decision Making (MADM) adalah menentukan nilai bobot untuk setiap atribut/kriteria, yang kemudian dilanjutkan dengan proses perankingan yang akan menyeleksi alternatif yang sudah diberikan. Pada dasarnya, ada 3 (tiga) pendekatan untuk mencari nilai bobot atribut, yaitu pendekatan subyektif, pendekatan obyektif dan 
pendekatan integrasi antara subyektif \& obyektif. Masing-masing pendekatan memiliki kelebihan dan kelemahan. Pada pendekatan subyektif, nilai bobot ditentukan berdasarkan subyektifitas dari para pengambil keputusan, sehingga beberapa faktor dalam proses perankingan alternatif bisa ditentukan secara bebas. Sedangkan pada pendekatan obyektif, nilai bobot dihitung secara matematis sehingga mengabaikan subyektifitas dari pengambil keputusan [3]. [3] :

Ada beberapa metode yang dapat digunakan untuk menyelesaikan masalah MADM antara lain

\author{
a. Simple Additive Weighting Method (SAW) \\ b. Weighted Product (WP) \\ c. Electre \\ d. Technique for Order Preference by Similarity to Ideal Solution (TOPSIS) \\ e. Analytic Hierarchy Process (AHP)
}

\title{
2.4 Weighted Product (WP)
}

Menurut Yoon dalam Kusumadewi (2006 : 79), Metode Weighted Product menggunakan perkalian untuk menghubungkan rating atribut, dimana rating setiap atribut harus dipangkatkan dulu dengan bobot atribut yang bersangkutan. Proses ini sama halnya dengan proses normalisasi.

Preferensi untuk alternatif diberikan sebagai berikut [3] :

$$
\mathrm{S}_{\mathrm{i}}=\prod_{j=1}^{n} X_{i j}{ }^{w j} \quad ; \text { dengan } \mathrm{i}=1,2, \ldots, \mathrm{m} .
$$

Dimana :

$$
\begin{array}{cll}
\mathrm{S} & : \text { Preferensi alternatif dianologikan sebagai vektor S } \\
\mathrm{X} & \vdots & \text { Nilai kriteria } \\
\mathrm{W} & : \text { Bobot kriteria/subkriteria } \\
\mathrm{i} & \vdots & \text { Alternatif } \\
\mathrm{j} & \vdots & \text { Kriteria } \\
\mathrm{n} & : & \text { Banyaknya kriteria }
\end{array}
$$

Dimana $\sum w_{j}=1 . W_{j}$ adalah pangkat bernilai positif untuk atribut keuntungan, dan bernilai negatif untuk atribut biaya.

Preferensi relatife dari setiap alternatif, diberikan sebagai :

$\begin{array}{ccl}\text { Dimana : } & & \prod_{j=1}^{n} X_{i j}{ }^{w j} \quad ; \text { dengan } \mathrm{i}=1,2, \ldots, \mathrm{m} . \\ & & \prod_{j=1}^{n}\left(X_{j}^{*}\right) \\ \mathrm{V} & \vdots & \text { Preferensi alternatif dianalogikan sebagai vektor } \mathrm{V} \\ \mathrm{X} & \vdots & \text { Nilai Kriteria } \\ \mathrm{W} & \vdots & \text { Bobot kriteria/subkriteria } \\ \mathrm{i} & \vdots & \text { Alternatif } \\ \mathrm{j} & \vdots & \text { Kriteria } \\ \mathrm{n} & \vdots & \text { Banyaknya kriteria } \\ * & : & \text { Banyaknya kriteria yang telah dinilai pada vektor } \mathrm{S}\end{array}$

\subsection{Siklus Hidup Pengembangan Sistem}

Menurut Jogiyanto [6]. Proses pengembangan sistem melewati beberapa tahapan dari mulai sistem itu direncanakan sampai dengan sistem tersebut diterapkan, dioperasikan dan dipelihara. Bila operasi yang sudah dikembangkan masih timbul kembali permasalahan-permasalahan yang tidak dapat diatasi dalam tahap pemeliharaan, maka perlu dikembangkan kembali suatu sistem untuk mengatasinya dan proses ini kembali ke tahap yang pertama, yaitu tahap perencanaan sistem. Siklus ini disebut dengan siklus hidup suatu sistem (systems life cycle). Daur atau siklus hidup dari pengembangan sistem merupakan suatu bentuk yang digunakan untuk menggambarkan tahapan utama dan langkah-langkah didalam tahapan tersebut dalam proses pengembangannya. Berikut langkah-langkah yang digunakan : 


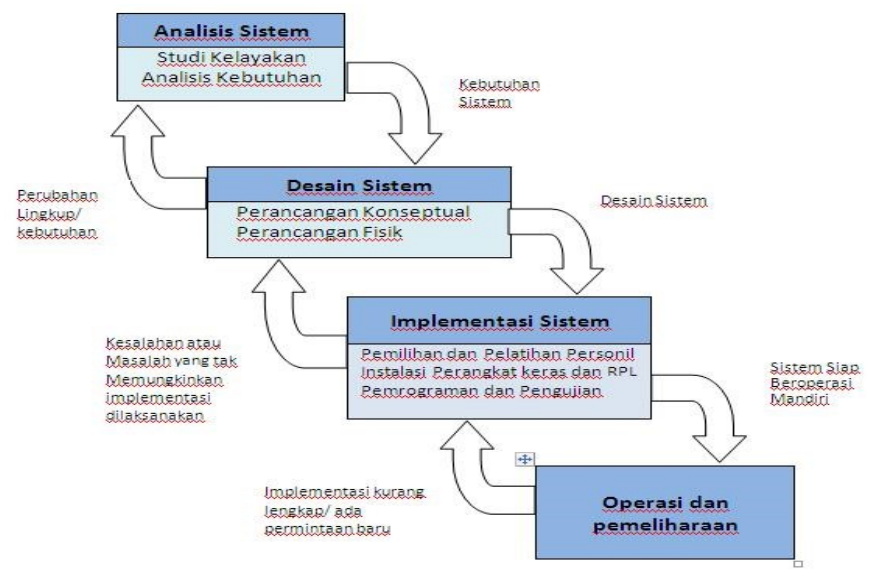

Gambar 1. Siklus Hidup Pengembangan Sistem

\subsection{Teknik Pengujian Sistem}

Pengujian sistem adalah elemen kritis dari jaminan kualitas perangkat lunak dan mempresentasikan kajian pokok dari spesifikasi, desain, dan pengkodean. Tujuan dari pengujian ini adalah diharapkan dengan minimal tenaga dan waktu untuk menemukan berbagai potensi kesalahan dan cacat.Harus didasarkan pada kebutuhan berbagai tahap pengembangan, desain dan dokumen lain atau program yang dirancang untuk menguji struktur internal, dan menggunakan contoh-contoh ini untuk menjalankan program untuk mendeteksi kesalahan.Pengujian sistem informasi harus mencakup pengujian perangkat lunak, pengujian perangkat keras dan pengujian jaringan.Pengujian hardware, jaringan pengujian berdasarkan indikator kinerja spesifik yang akan digunakan di sini pengujian lebih jauh adalah pengujian perangkat lunak [7].

\section{a. White Box}

Pengujian white-box (glass box), adalah metode desain test case yang menggunakan struktur kontrol desain prosedural untuk memperoleh test case. Dengan menggunakan metode pengujian whitebox, perekayasa sistem dapat melakukan test case untuk memberikan jaminan bahwa :

1. Semua jalur independen pada suatu modul ditelusuri minimal 1 (satu) kali.

2. Semua jalur keputusan logis True/False dilalui.

3. Semua loop dieksekusi pada batas yang tercantum dan batas operasionalnya.

4. Struktur data internal digunakan agar validitas terjamin.

Pengujian white-box bisa dilakukan dengan pengujian basis path, metode ini merupakan salah satu teknik pengujian struktur kontrol untuk menjamin semua statemen dalam setiap jalur independen program dieksekusi minimal 1 kali dan tidak menjumpai error message. Perhitungan jalur independen dapat dilakukan melalui metrik Cyclomatic Complexity. Sebelum menghitung nilai Cyclomatic Complexity, harus diterjemahkan desain prosuderal ke grafik alir, kemudian dibuat flow graphnya [7]

b. Black-Box

Pengujian Black-Box berusaha menemukan kesalahan dalam kategori :

1. Fungsi tidak benar atau hilang.

2. Kesalahan antar muka.

3. Kesalahan pada struktur data (pengaksesan basis data).

4. Kesalahan inisialisasi dan akhir program.

5. Kesalahan performasi.

Pengujian ini berfokus pada persyaratan fungsional perangkat lunak dan merupakan komplemen dari pengujian White-Box. Hal ini dapat dicapai melalui :

a. Pengujian Graph-based: dimulai dengan membuat grafik sekumpulan node yang mempresentasikan objek (misal New File, Layar baru dengan atributnya), link (hubungan antar objek), node-weight (misal nilai data tertentu seperti atribut layar, perilaku), dan link-weight (karakteristik suatu link, misal menu select).

b. Equivalence Partitioning: membagi domain input untuk pengujian agar diperoleh kelas-kelas kesalahan (misal kelompok data karakter, atau atribut yang lain).

c. Analisis Nilai Batas: pengujian berdasarkan nilai batas domain input.

d. Pengujian Perbandingan: disebut juga pengujian back-to-back yang diterapkan pada pada suatu versi perangkat lunak atau perangkat lunak redundan untuk memastikan konsistensinya 


\section{Metode}

Adapun metode atau cara penelitian yang dilakukan dapat diuraikan sebagai berikut:

a. Tahap Analisis : pada tahap ini dilakukan analisis sistem yang terdiri dari analisis sistem dan kebutuhan sistem

b. Tahap Desain : pada tahap ini dilakukan desain sistem yakni desain model, desain output, desain input, desain menu utama, dan desain database.

c. Tahap Produksi/Pembuatan : pada tahap ini dilakukan setelah tahap desain selesai. Dalam pembuatan sistem ini digunakan bahasa pemrograman Microsoft Visual Basic 6.0, Databasenya menggunakan MySQL dan Report atau laporan menggunakan Crystal Report 8.5.

d. Tahap Pengujian : tahap ini dilakukan setelah semua modul selesai dibuat, dan program dapat berjalan, dimana seluruh perangkat lunak, program tambahan, dan semua program yang terlibat dalam pembangunan sistem diuji untuk memastikan sistem dapat berjalan sesuai dengan rancangan atau belum. Pengujian sistem dilakukan dengan menggunakan data yang telah didapat pada tahap analisa sistem. Jika terjadi hal-hal yang tidak sesuai dengan yang diharapkan, kemudian dilakukan revisi atau perbaikan agar sistem tersebut dapat dioperasikan dengan baik dan siap untuk diiplementasikan. Pengujian yang dilakukan dengan teknik pengujian perangkat lunak yang telah ada yaitu pengujian White Box dan pengujian Black Box.

e. Tahap Implementasi : pada tahap ini dilakukan penerapan sistem pada kantor BP4K Kota Gorontalo.

\section{Hasil}

Berikut beberapa tampilan form dari aplikasi sistem pendukung keputusan Pemilihan Penyuluh Lapangan Keluarga Berencana Teladan yang sudah dibuat:

a. Form Entry Penilaian Penyuluh

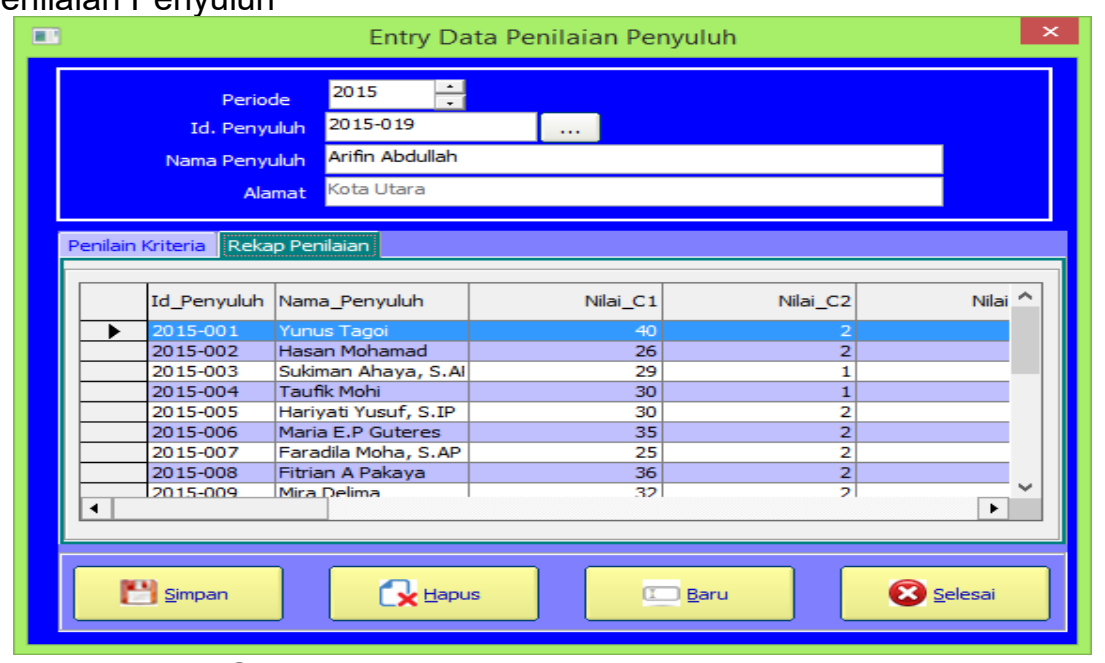

Gambar 2. Entry Data Penilaian Penyuluh

b. Tampilan Hasil dari Proses Perhitungan Vektor S

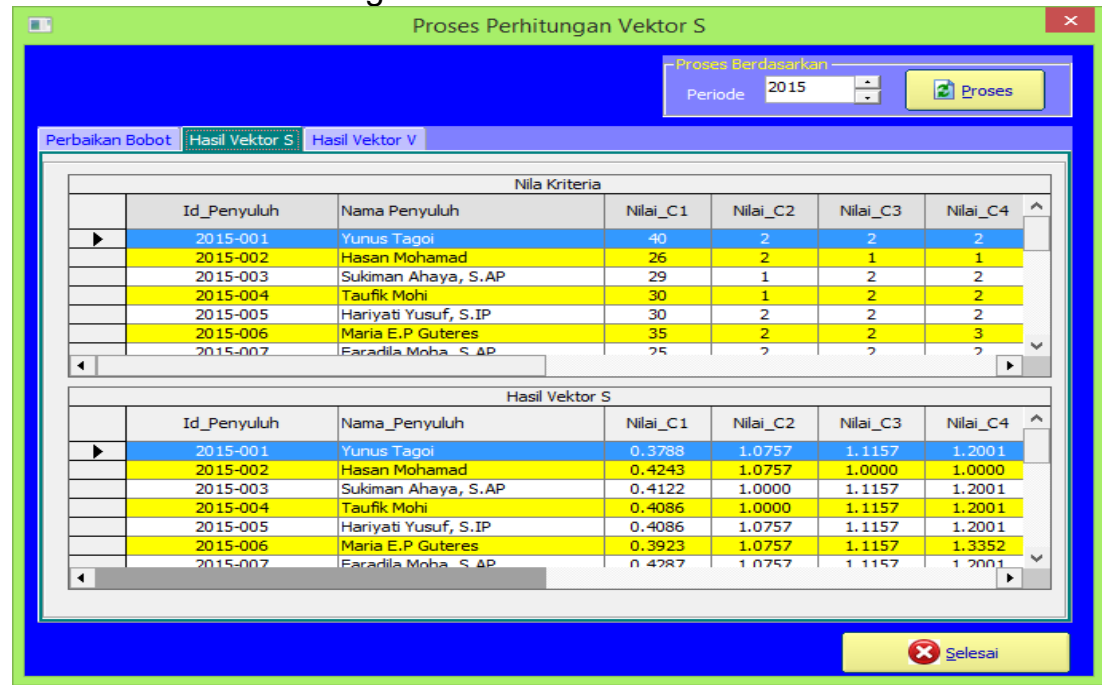

Gambar 3. Tampilan Hasil Proses Perhitungan Vektor S 
c. Tampilan Laporan Hasil Perhitungan Vektor V

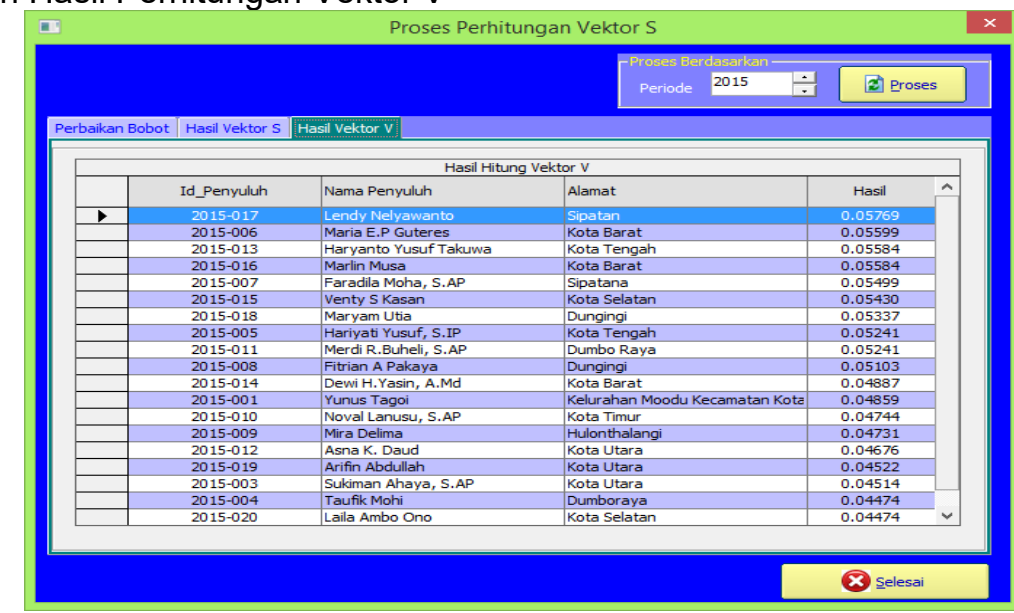

Gambar 4. Laporan Data Hasil Perhitungan Vektor V

Berdasarkan hasil penelitian diatas, dilakukan perhitungan manual dengan mengambil 3 data sebagai sampel untuk proses perhitungan. Adapun data awal dan kriteria yang digunakan dalam perhitungan ini adalah sebagai berikut [2]:

Tabel 1. Kriteria Pemilihan Penyuluh Lapangan Keluarga Berencana

\begin{tabular}{clcc}
\hline Kode & \multicolumn{1}{c}{ Nama Kriteria } & Bobot & $\begin{array}{c}\text { Jenis } \\
\text { Kriteria }\end{array}$ \\
\hline C1 & Usia Maksimal 60 Tahun & 5 & Cost \\
C2 & Status Penyuluh (Pegawai Negeri Sipil) & 2 & Benefit \\
C3 & Memiliki Tanggungan Maksimal 2 Anak & 3 & Benefit \\
C4 & Suami/lstri Menggunakan Alat Kontrasepsi MKJP & 5 & Benefit \\
C5 & Minimal 4 Tahun Sebagai Penyuluh KB & 4 & Benefit \\
\hline
\end{tabular}

Tabel 2. Nilai Alternatif Pada Setiap Kriteria

\begin{tabular}{cccccc}
\hline \multirow{2}{*}{ Alternatif } & \multicolumn{5}{c}{ Kriteria } \\
\cline { 2 - 6 } & C1 & C2 & C3 & C4 & C5 \\
\hline A1 & 40 & 2 & 2 & 2 & 6 \\
A2 & 26 & 2 & 1 & 1 & 4 \\
A3 & 29 & 1 & 2 & 2 & 4 \\
\hline
\end{tabular}

Sebagai sampel dalam perhitungan ini adalah A1=Yunus Tagoi, A2=Hasan Mohammad, A3 =Sukiman Ahaya, S.AP. Untuk menyelesaikan kasus diatas dilakukan tahapan sebagai berikut:

Tahap 1 :

Sebelumnya akan dilakukan perbaikan bobot terlebih dahulu. Bobot awal $W=(5,2,3,5,4)$, akan diperbaiki sehingga total bobot $\sum w_{j}=1$, dengan cara :

$$
\mathrm{w}_{\mathrm{j}}=\frac{\mathrm{w}_{\mathrm{j}}}{\sum \mathrm{w}_{\mathrm{j}}}
$$

$\mathrm{W}_{1}=\frac{5}{5+2+3+5+4}=\frac{5}{19}=0,2632$
$\mathrm{~W}_{2}=\frac{2}{5+2+3+5+4}=\frac{2}{19}=0,1053$
$\mathrm{~W}_{3}=\frac{3}{5+2+3+5+4}=\frac{3}{19}=0,1579$
$\mathrm{~W}_{4}=\frac{5}{5+2+3+5+4}=\frac{5}{19}=0,2632$


$W 5=\frac{4}{5+2+3+5+4}=4=0,2105$

\section{Tahap 2 :}

Kemudian vektor $\mathrm{S}$ dihitung berdasarkan persamaan 1 sebagai berikut :

$S_{1}=\left(40^{-0,2632}\right)\left(2^{0,1053}\right)\left(2^{0,1579}\right)\left(2^{0,2632}\right)\left(6^{0,2105}\right)=0,7955$
$S_{2}=\left(2^{-0,2632}\right)\left(2^{0,1053}\right)\left(1^{0,1579}\right)\left(1^{0,2632}\right)\left(4^{0,2105}\right)=0,6110$
$S_{3}=\left(2^{-0,2632}\right)\left(1^{0,1053}\right)\left(2^{0,1579}\right)\left(2^{0,2632}\right)\left(4^{0,2105}\right)=0,7390$

\section{Tahap 3 :}

Nilai vektor $\mathrm{V}$ yang akan digunakan untuk perankingan dapat dihitung berdasarkan persamaan 2 sebagai berikut :

$\mathrm{V} 1=\frac{0,7955}{0,7955+0,6110+0,7390}=0,37078$
$\mathrm{~V} 2=\frac{0,6110}{0,7955+0,6110+0,7390}=0,34443$
$\mathrm{~V} 3=\frac{0,7390}{0,7955+0,6110+0,7390}=0,28479$

Dari Hasil Perhitungan Vektor V diatas, maka di dapat Kesimpulan bahwa :

Nilai Terbesar ada pada $V_{1}$ sehingga alternatif $A_{1}$ adalah alternatif yang terpilih sebagai alternatif terbaik. Dengan kata lain, Yunus Tagoi yang akan dipilih sebagai Penyuluh Lapangan Keluarga Berencana (PLKB) Teladan.

\section{Kesimpulan}

Berdasarkan hasil penelitian di atas dapat ditarik kesimpulan sebagai berikut :

1. Sistem Pendukung Keputusan pemilihan Penyuluh Lapangan Keluarga Berencana (PLKB) Teladan dengan menggunakan metode Weighted Product (WP) dapat digunakan untuk membantu pihak pengambil keputusan dalam menentukan PLKB Teladan.

2. Metode Weighted Product (WP), dapat digunakan oleh Badan Badan Pemberdayaan Masyarakat Perempuan dan Keluarga Berencana Kota Gorontalo dalam penentuan Penyuluh Lapangan Keluarga Berencana (PLKB) Teladan.

\section{Daftar Pustaka}

[1] BKKBN, 2006, Buku Pegangan Penyuluh Keluarga Berencana. Jakarta: Biro Kepegawaian Dan Direktorat Institusi Dan Peran Serta

[2] BPMPKB, 2015, Panduan Pemilihan Penyuluh Lapangan Keluarga Berencana (PLKB) Berprestasi. Gorontalo

[3] Kusumadewi, dkk.,2006, Fuzzy Multi-Atribute Decision Making (Fuzzy MADM), Yogyakarta : Graha IImu

[4] Turban, dkk, 2005, Decision Support Systems and Intelligent Systems, Yokyakarta : Andi

[5] Kusrini, 2007, Konsep dan Aplikasi Sistem Pendukung keputusan, Yokyakarta: Andi.

[6] Jogiyanto, 2005, Analisa dan Desain Sistem Informasi : Pendekatan Terstruktur Teori dan Praktek Aplikasi Bisnis, Yokyakarta: Andi Offset

[7] Pressman, R.S. 2002, Rekayasa Perangkat Lunak : Pendekatan Praktis (Buku I), Yogyakarta : Andi. 